\title{
Sudden post-midnight decrease in equatorial F-region electron densities associated with severe magnetic storms
}

\author{
D. R. Lakshmi, B. Veenadhari, R. S. Dabas, B. M. Reddy \\ National Physical Laboratory, New Delhi - 110012, India
}

Received: 4 July 1995 / Revised: 8 October 1996 / Accepted: 15 October 1996

\begin{abstract}
A detailed analysis of the responses of the equatorial ionosphere to a large number of severe magnetic storms shows the rapid and remarkable collapse of F-region ionisation during post-midnight hours; this is at variance with the presently accepted general behaviour of the low-latitude ionosphere during magnetic storms. This paper discusses such responses as seen in the ionosonde data at Kodaikanal (Geomagn. Lat. $0.6 \mathrm{~N}$ ). It is also observed that during magnetic storm periods the usual increase seen in the $h^{\prime} F$ at Kodaikanal during sunset hours is considerably suppressed and these periods are also characterised by increased foF 2 values. It is suggested that the primary process responsible for these dramatic pre- and postmidnight changes in foF 2 during magnetic storms could be due to changes in the magnitude as well as in the direction of usual equatorial electric fields. During the post-midnight periods the change in electric-field direction from westward to eastward for a short period causes an upward $\boldsymbol{E} \times \boldsymbol{B}$ plasma drift resulting in increased h'F and decreased electron densities in the equatorial region. In addition, it is also suggested that the enhanced storminduced meridional winds in the thermosphere, from the poles towards the equator, may also cause the decreases in electron density seen during post-midnight hours by spatially transporting the F-region ionisation southwards away from Kodaikanal. The paper also includes a discussion on the effects of such decreases in ionisation on low-latitude HF communications.
\end{abstract}

\section{Introduction}

The ionospheric effects of magnetic storms have been studied in great detail by a number of workers and many excellent papers have been published. While the documented effects are prominent at mid- and high latitudes, the ionosphere at equatorial latitudes was expected to be invulnerable or at worst only marginally affected
(Matsushita, 1959; Raja Ram and Rastogi, 1969; Lakshmi et al., 1983). In addition to providing an excellent opportunity to study the interplay between the plasma and magnetic field, this topic is also of vital importance in $\mathrm{HF}$ radio communications.

Radio communications in the HF band are frequently disrupted during magnetic storms. Short-term predictions are issued in many countries with respect to the expected intensity of the storm, which essentially means the expected Main Phase decrease in the field. The storm-induced departures in the relevant ionospheric parameters are then estimated using models that are appropriate to the particular regions and alternative frequencies are pressed into service. However, the existing models had encouraged complacency amongst radio communicators regarding departures in the equatorial ionosphere, and the magnetic-storm predictions were not taken seriously. By studying a large number of severe storms we have found that such complacency is ill-founded and effects can be severe because it has been observed, on a large number of occasions, that in the post-midnight periods the foF2 (critical frequency of F-layer) values collapse to levels significantly lower than their monthly median values during severe storms. The main objective of the present study is to examine this sudden fall in the night-time ionisation levels during severe magnetic storms. The importance of this study for HF services can be appreciated if it is realised that any dramatic decrease in night-time foF2 will cause serious problems at equatorial latitudes because of the steeply increasing atmospheric radio noise with decreasing frequency in the HF band.

\section{Data analysis and results}

The study is based on the ionosonde data from Kodaikanal (Geogr. Lat. 10.6 N, Geogr. Long. 75 E; Geomagn. Lat. 0.6 N), an equatorial station in the Indian zone. About 20 severe magnetic storms, for which the maximum of the K-index reached values of 7 or more as reported by the Alibag (India) magnetic 
observatory (Geomagn. Lat. $9.5^{\circ} \mathrm{N}$ ) are considered for the study. The maximum negative excursion of Dst for these various storms generally varied between 150 and $300 \mathrm{nT}$. Though a large number of these storms occurred in the equinoctial months, care has been taken to have adequate seasonal representation in the data sets chosen for this study. The analysis of ionospheric data is restricted mainly to F-region parameters, namely the critical frequencies (foF2), peak heights (hmF2) and the base height of F-layer ( $\left.h^{\prime} \mathrm{F}\right)$. While there are several ionospheric effects associated with these storms, one outstanding feature which forms the focus of this paper is the large and sharp collapse of F-region ionisation around midnight during most of the events. In fact, it has been observed that the night-time foF2 values rapidly collapse by as much as $5-6 \mathrm{MHz}$ within an hour at the equatorial station Kodaikanal. The ionisation levels appear to fall at a rate greater than the average rates of the night-time behaviour of the $F$ region at these latitudes. It has also been observed that this collapse in ionisation level can occur during different phases of the storm. Instances of ionisation collapse have been observed both during the progress of main phase as well as during the recovery phase of the storm. Accompanying ionospheric peak-height variations are not impressive and do not seem to follow any particular pattern. To illustrate these features of the night-time collapse of the equatorial $\mathrm{F}$ region during magnetic storms, three specific storms were chosen for discussion in this paper. These storms are not immediately preceded by any other event and offer a clean background.

\subsection{SC storm of 24 March 1991}

This severe storm occurred with a well-defined SC at 0300 UT (0800 LT) on 24 March 1991. The maximum negative excursion of Dst was around $300 \mathrm{nT}$ and the Alibagh magnetic observatory reported a maximum $\mathrm{K}$-index of 7 . Figure 1 shows the Dst variations, along with the variation of foF $2, \mathrm{hmF} 2$ and $\mathrm{h}^{\prime} \mathrm{F}$, observed at Kodaikanal (Geomagn. lat. 0.6 N), an equatorial station in the southern part of India. The most striking feature to be observed in this figure is the dramatic collapse of F-region ionisation as evidenced by the foF2 values (broken curve) on the night of 24-25 March 1991 when the main phase of the storm was in progress. The sharp fall in ionisation levels continued up to the pre-dawn hours and recovered rapidly with onset of local sunrise. The fall in the foF 2 values during this period $0100-0500$ LT was rapid, with foF2 falling from 9.5 to $3.0 \mathrm{MHz}$. The peak heights $(\mathrm{hmF} 2)$ are in general at increased levels, when compared to the monthly median values, by $50-100 \mathrm{~km}$.

However, the variations in $h^{\prime} F$ (Fig. 1) reveal several interesting features. The most obvious is the large increase in $\mathrm{h}^{\prime} \mathrm{F}$ between 0200 and $0500 \mathrm{LT}$ on $25 \mathrm{March}$ 1991. The occurrence of this increase is coincident with the mentioned sharp fall in foF2. It is also pointed out that the local time of this increase in $h^{\prime} \mathrm{F}$ at $0200 \mathrm{LT}$ is earlier than the usual quiet-day increase in $\mathrm{h}^{\prime} \mathrm{F}$, which usually occurs during the dawn hours (0500-0600 LT, see the median curve), and occurs prior to the start of the recovery phase. This phenomenon of a decrease in foF 2 accompanied by increase in $h^{\prime} F$ levels, to a lesser extent, can be observed also on the night of 25-26 March 1991 when the recovery phase was still in progress with Dst values around $-150 \mathrm{nT}$.

The normal behaviour of foF2 and h'F at Kodaikanal during evening to midnight hours is such that there is an increase in $h^{\prime} F$ and a corresponding decrease in foF2 during sunset hours as seen from median curves. But during magnetic-storm periods the rise in $h^{\prime} F$ is observed to be comparatively less than the median values. Corresponding to this the foF 2 values were observed to be higher than the median values (see Fig. 1 on 26 March 1991 during pre-midnight hours).

\subsection{Storm of 9 April 1990}

The SC occurred at around 0842 UT (1342 LT) on 9 April 1990. Although in the initial stages the mainfield decrease was gradual, this storm developed into a very severe one, with the Dst values plunging to as low as -280 nT by midnight of 10 April 1990 (Fig. 2). It can be seen from Fig. 2 that the night-time period of 10-11 April was characterised by a steep fall in the foF2 values starting around midnight. The hmF2 values exhibit a periodic variation on the night of 10-11 April. A sharp increase in $h^{\prime} F$ coincident with the recovery phase beginning can also be seen from the figure at $0000 \mathrm{LT}$ on 11 April. An unusal increase in foF2 during premidnight hours accompanied by a modest rise in $h^{\prime} \mathrm{F}$ can also be noticed on the night of 9-10 April 1990. Similarly on 11 th evening when the storm was recovering, the $h^{\prime} F$ rise was also suppressed and was associated with the increased foF 2 values as compared to median values. This observation is also similar to what has been observed on the evening of 26 March 1991 for the storm described in Sect. 2.1.

\subsection{Storm of 8 November 1991}

This severe storm, with SC at 0647 UT (1147 LT), 8 November 1991, is characterised by a very rapid decrease in the H-field. The Dst values dropped to a value of $-360 \mathrm{nT}$ within $12 \mathrm{~h}$ of the SSC of this storm (Fig. 3). As can be seen from this figure, on the night of 8-9 November 1991 a steep decrease of about $8.0 \mathrm{MHz}$ occurred within an hour: the period 0300-0400 LT. This dramatic decrease in foF 2 was not accompanied by any significant change in hmF2. However, this decrease in foF 2 was accompanied by a steep increase in $h^{\prime} F$ from about 250 to $380 \mathrm{~km}$ during the period $0300-0500 \mathrm{LT}$. This enhancement occurs earlier than the enhancement in the median value $(0500-0600 \mathrm{LT})$. The recovery phase of the storm commenced at 0700 LT on 9 November 1991. On the night of 9-10 November 1991, the foF2 values also decreased sharply, but to a lesser extent. 


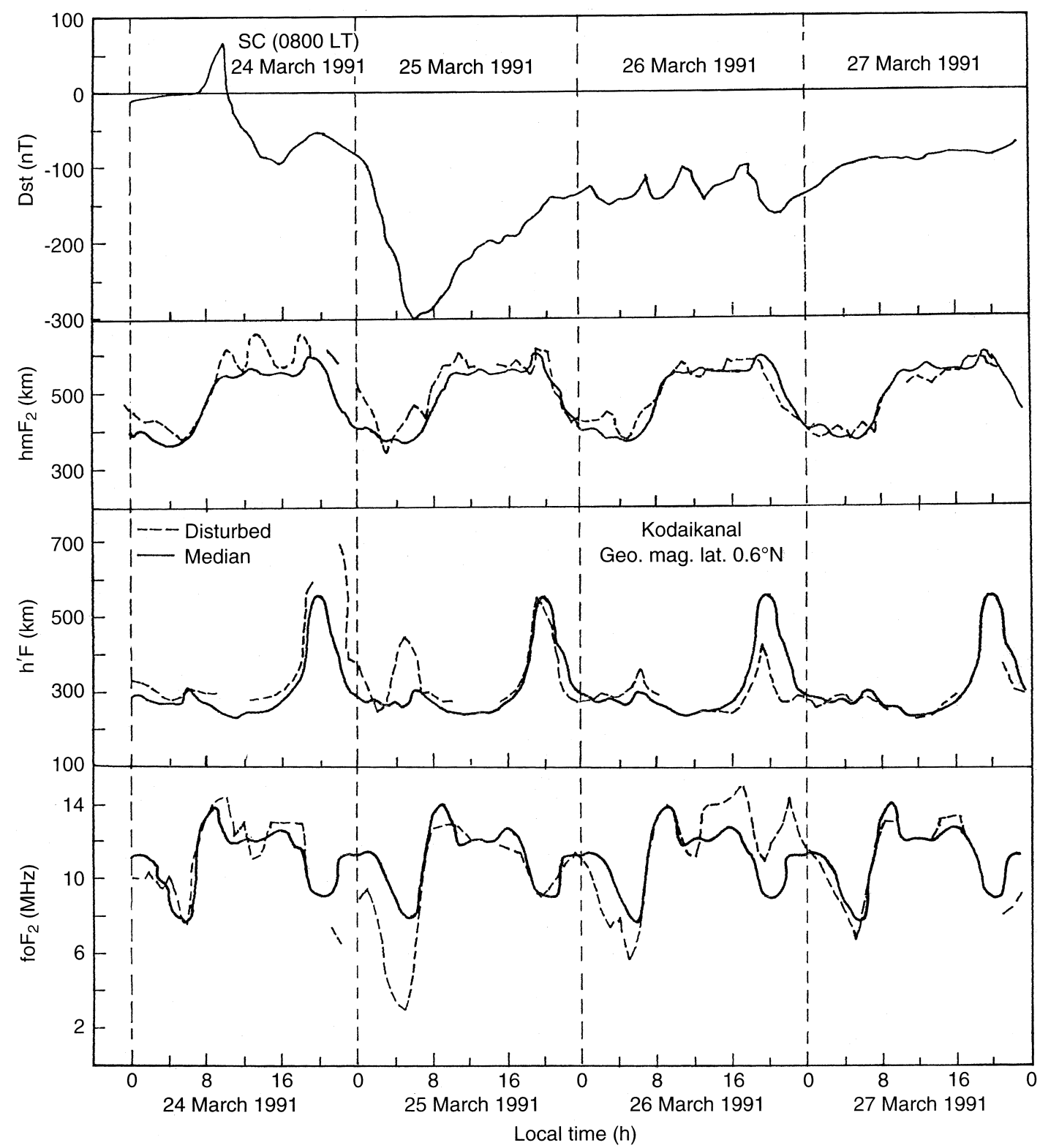

Fig. 1. Shows foF2, h'F and hmF2 data for Kodaikanal for the 24 March 1991 storm along with respective monthly median values. Dst variation for the storm period is shown in the top panel

\subsection{Short summary}

To summarize the observations the following points are made:

(i) A dramatic decrease in night-time ionisation levels can occur, starting at around midnight and continuing through the pre-dawn hours during severe storms.

(ii) The decrease can be very steep, with a fall in excess of $5 \mathrm{MHz}$ within an hour or so.

(iii) The variations in peak height $(\mathrm{hmF} 2)$ during these periods are not as dramatic as those seen in foF 2 , but are often characterised by significant fluctuations.

(iv) The $h^{\prime} F$ values show some unusual increases during periods of night-time decrease in foF 2 . (v) During the storm the usual evening rise in $h^{\prime} \mathrm{F}$ levels is suppressed and these periods are associated with increased foF2 values as compared to medians.

To examine further the features of dramatic fall in foF2 and sharp increases in $h^{\prime} \mathrm{F}$ observed during postmidnight hours, ionosonde data from Kodaikanal pertaining to some nine storms is plotted in Fig. 4 on a seasonal basis. The figure shows data for only those nights when these features were observed, but not for the entire storm periods. It can be noted from the figure that these simultaneous effects in foF 2 and $h^{\prime} F$ do not show any particular seasonal dependence. It may also be mentioned here that the local maximum K-index (Alibag magnetic observatory, India) was either 7 or more in all the cases. As can be seen from Fig. 4, the h'F 


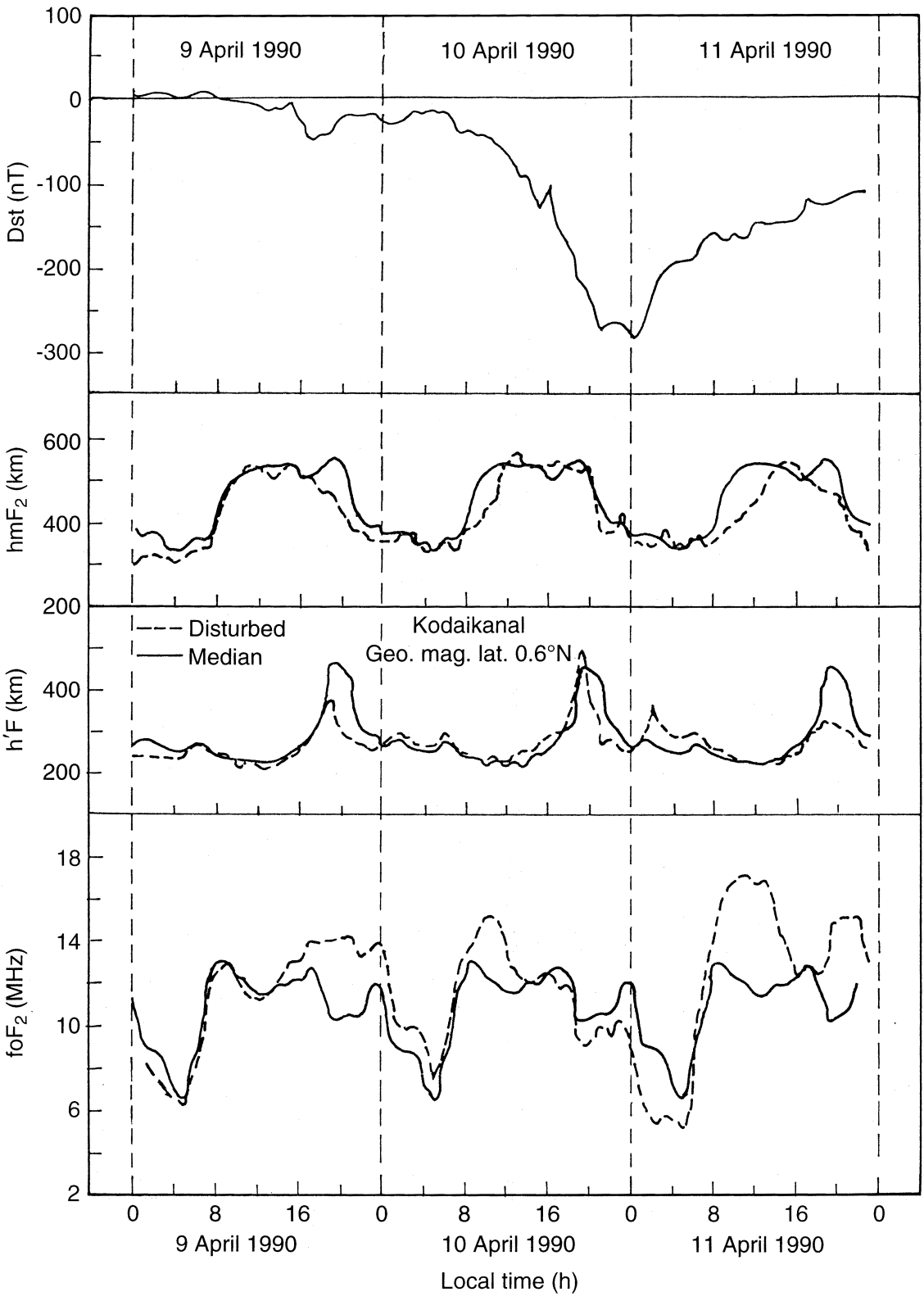

Fig. 2. Shows foF2, h'F and hmF2 data for Kodaikanal for the 9 April 1990 storm along with respective monthly median values. Dst variation for the storm period is shown in the top panel and foF2 variations during pre-midnight hours are also similar to the storms discussed in Sect. 2.1-3.

\subsection{Severe storm effects on MUFs}

The departures in the maximum useable frequencies (MUFs) for any HF link are determined by the simultaneous variations in the foF 2 and $\mathrm{hmF} 2$ values. It is also known that the foF 2 variations prevail over the hmF2 variations in controlling MUF values, especially for circuits shorter than $1000 \mathrm{~km}$ (Rush et al., 1974; Lakshmi et al., 1983). To demonstrate the variations in MUFs during severe storms, the percentage departures in MUF (3000) F2 values (maximum useable frequencies for a path length of $3000 \mathrm{~km}$ ) from their monthly median values have been computed for the storm periods. Figure 5 shows these MUF (3000) F2 departures for Kodaikanal for the severe storm of 24 March 1991; the foF2 and hmF2 values along with the monthly medians are also included in the figure. Of particular interest are the large negative departures during the night of 24-25 March 1991, the worst situation being around midnight when the values were suppressed by as much as $60 \%$, which can result in total failure of communication in HF bands.

\section{Discussion}

Some excellent work on ionospheric storms has been published during the past four decades. It has been difficult or impossible to develop any unique theory that can explain the ionospheric responses at all latitudes for 


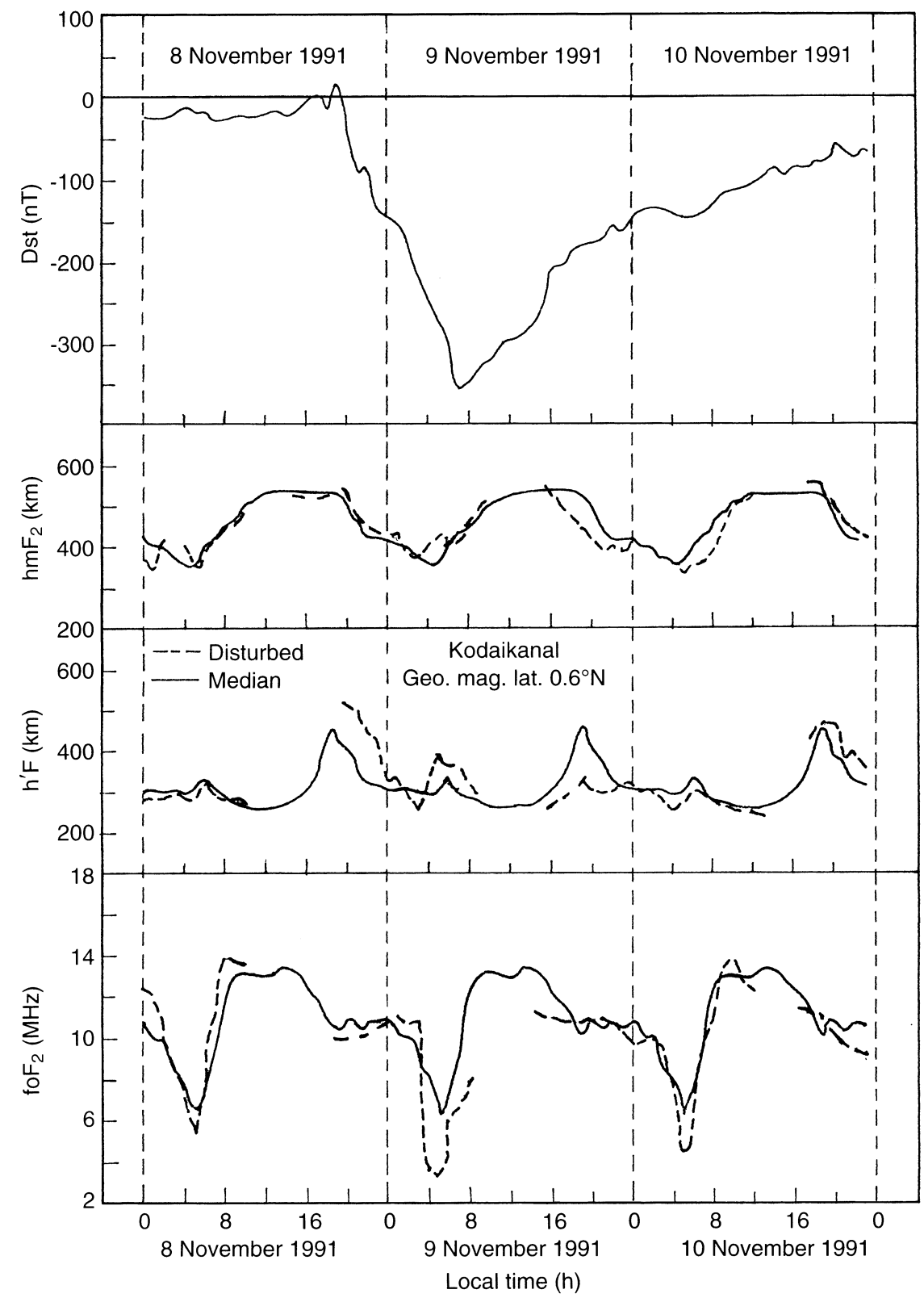

Fig. 3. Shows foF $2, h^{\prime} F$ and $h m F 2$ data for Kodaikanal for the 8 November 1991 storm along with respective monthly median values. Dst variation for the storm period is shown in the top panel storms in general. Electrodynamic drifts, meridional winds, rapid changes in atmospheric heating and thermal expansion etc., have been invoked (Reddy et al., 1967; Raja Ram et al., 1971; Rishbeth, 1975; Dabas and Jain, 1985; Fejer et al., 1990; Abdu et al., 1990; Fuller-Rowell, 1994), with different degrees of success to suit particular events.

There are reports on equatorial and low-latitude neutral temperatures far exceeding the MSIS-86 predictions (Hedin, 1987) for disturbed conditions. Biondi and Meriwether (1985) observed from Fabry-Perot measurements night-time Tn values enhanced by as much as 400-500 K during disturbances at low latitudes. Gross (1985) also reported some unusual heating events from AE-E satellite measurements during disturbed conditions. One possible heat source for such heating at low latitudes could be ring-current protons precipitating in the equatorial $\mathrm{F}$ region (Tinsley, 1979; Sahai et al., 1988). While reporting the ionospheric effects of the severe storm of 13 March 1989 at equatorial and low latitudes, Lakshmi et al. (1991) did consider these enhanced neutral temperatures, but the magnitude of observed neutral temperature enhancements could account for only a part of the large night-time collapse of F-region ionisation.

The results described can in general be divided into two categories; storm-period variations of foF 2 and h'F during pre- and post-midnight periods. During the premidnight periods increases in foF 2 are found to be associated with a decrease in $\mathrm{h}^{\prime} \mathrm{F}$ as compared to median values, whereas during post-midnight periods sharp decreases in foF2 are associated with increases in $h^{\prime} \mathrm{F}$. It is well known that in equatorial $\mathrm{F}$ region, $\boldsymbol{E} \times \boldsymbol{B} \mathrm{drift}$ velocity (which generates the fountain and the anomaly) 


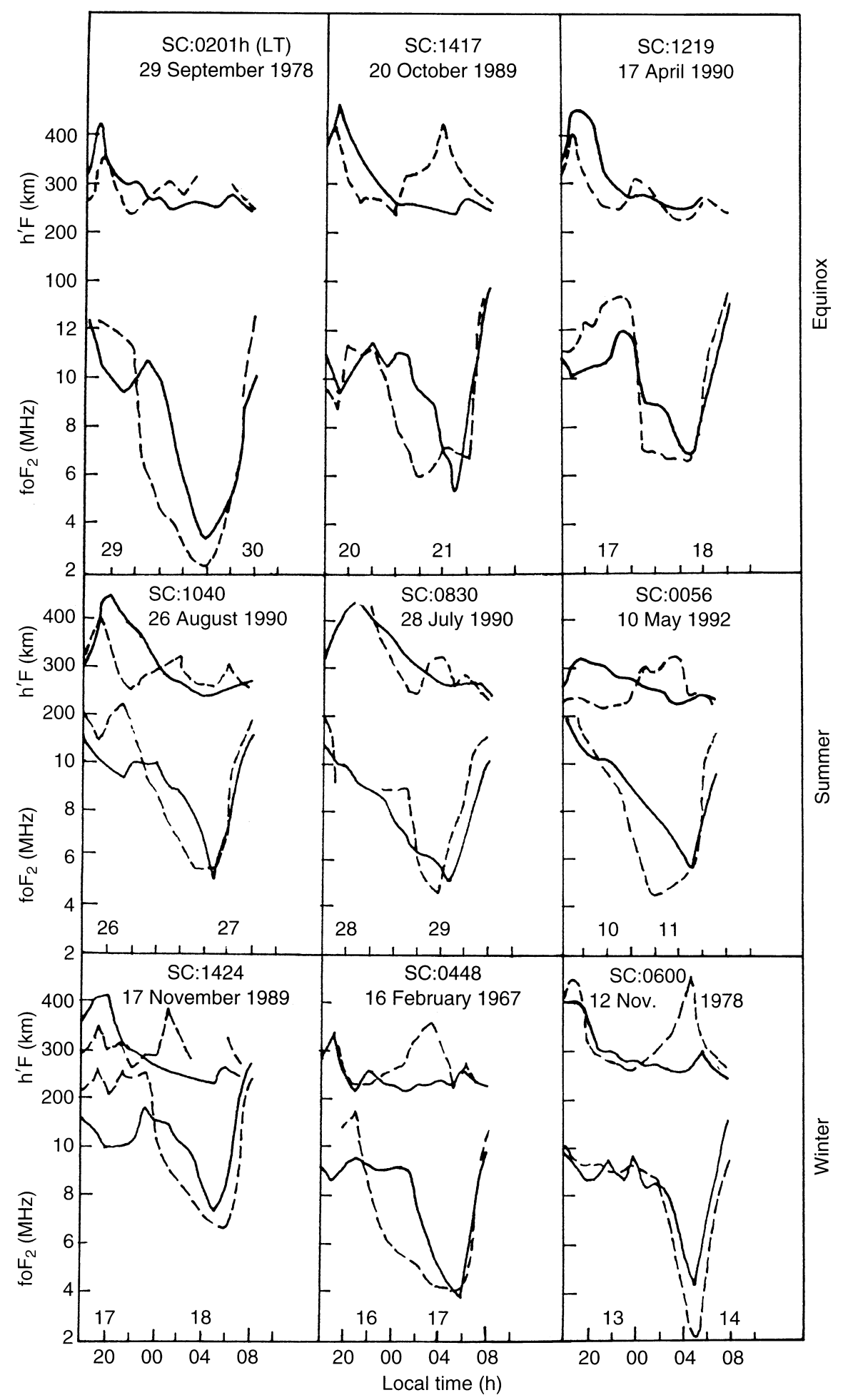

Fig. 4. Depicts sudden decrease in night-time foF2 which occurs simultaneously with sharp rise in h'F at Kodaikanal (geomagn. lat. $0.6 \mathrm{~N}$ ) for nine specific storms on seasonal basis. The dashed line represents disturbed days while the continuous line represents the monthly medians is characterised by a pre-reversal strengthening near sunset (due to enhanced eastward electric field) and is thought to be responsible for many of the ionospheric phenomena (e.g. post-sunset-hour secondary maxima in TEC and NmF2) occurring at equatorial anomaly latitudes during evening-midnight periods. In fact $\boldsymbol{E} \times \boldsymbol{B}$ drifts are most important in affecting the ionisation distribution at low latitudes. The usual evening-hour rise in $h^{\prime} F$ values as seen in the median plots of all the figures is indicative of enhancement of eastward electric field magnitude. Also, this rise in $\mathrm{h}^{\prime} \mathrm{F}$ is always associated with a decrease in foF2 at Kodaikanal, which means the $\boldsymbol{E} \times \boldsymbol{B}$ drift or the plasma fountain was operative over there. The explanations for the decrease in $h^{\prime} \mathrm{F}$ and increase in foF2 during evening to midnight hours is as follows: the predominant flow in the ever present ring 


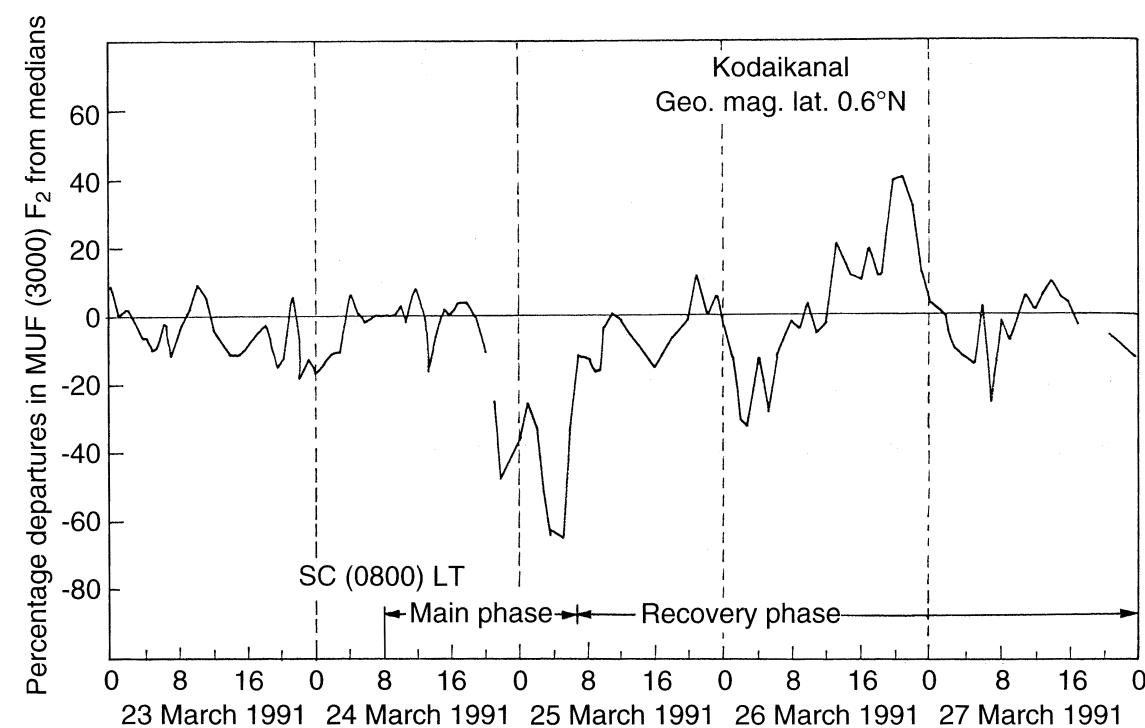

Local time $(h)$
Fig. 5. Percentage departures in MUF (3000) F2 values from their monthly values during 24 March 1991 storm current is westward, which is responsible for the depression in Dst. As already discussed, that in the pre-sunset-period F-layer height normally rises, but during magnetic storms, intensification of ring current in this time-period directly or indirectly has the effect of decreasing the local eastward electric field and thus reducing the layer height as seen in the h'F plots of the figures presented here. The weakened upward $\boldsymbol{E} \times \boldsymbol{B}$ drift results in increased foF 2 values at Kodaikanal as seen in the results described here.

At night, zonal westward electric fields produce a downward $\boldsymbol{E} \times \boldsymbol{B}$ drift. The effect, however, of the ring current in the midnight and post-midnight periods when $\mathrm{h}^{\prime} \mathrm{F}$ is normally falling and the electric field is westward is to create momentarily an eastward electric field and raise the layer's height for a short period (Dabas et al., 1989; Aarons, 1991). In the present results the rise in h'F seen during post-midnight hours is thus indicative of change of electric field direction from westward to eastward. This in turn provides an upward $\boldsymbol{E} \times \boldsymbol{B} \mathrm{drift}$ and will cause a loss of plasma from equatorial region as indicated by associated decrease in the foF 2 values at Kodaikanal in the post-midnight hours.

There may be other forcing fators contributing to the sharp collapse of ionisation during post-midnight hours. One of the plausible mechanisms is that the $\mathrm{N} 2$, vibrationally excited by the charge-exchanged neutral particles originated in the ring current, might decrease the foF 2 and increase $h^{\prime} \mathrm{F}$ due to the reaction

$\mathrm{N}_{2}(\mathrm{v})+\mathrm{O}^{+} \longrightarrow \mathrm{NO}^{+}+\mathrm{N}$,

where $\mathrm{NO}^{+}$is quickly recombined

Another factor to be considered is the role of meridional winds in influencing the equatorial ionosphere. In recent years there has been incontrovertible evidence from both satellites as well as ground-based experiments demonstrating the influence of meridional winds modulating the equatorial ionosphere (Biondi et al., 1991; Krishna Murthy et al., 1990; Krishna Murthy and Hari, 1992; Miller et al., 1986; Meriwether et al.,
1986). Krishna Murthy and Hari (1992) describe the night-time thermospheric winds near the geomagnetic equator (Trivandrum) in southern India during different seasons and also under disturbed conditions. It was shown that during winter the meridional wind is mainly poleward (northward) during the night, except for a few hours in the early morning when it reverses to equatorward, while at the equinoxes it is equatorward during the period 2000-2300 LT and is followed by a strong poleward wind during the midnight hours 0000-0200 LT before it turns equatorwards. They also reported for a winter magnetic storm the behaviour of meridional winds to be completely different from the seasonal average.

With the existing information on nocturnal equatorward thermospheric winds, which should intensify during severe storms, it can be hypothesised that during the equinoxes the winds from both the poles should converge at the geographic equator. During other seasons, the winds should converge to a point in the winter hemisphere. In fact, storm simulations using the UCL coupled ionosphere-thermosphere model showed cross-equatorial winds driven by Joule heating even under equinox conditions (Fuller-Rowell et al., 1994). Thus, during the equinoxes and summer, there should be strong equatorward (southward) winds over Kodaikanal, some $10^{\circ}$ north of the geographic equator. This meridional wind can drive the ionisation along the nearhorizontal magnetic field and physically carry it to points south of Kodaikanal. When such forced migration takes place, the depleted plasma can not be replenished either from below or above because the magnetic field is horizontal and because it is night-time. Thus, as the plasma moves over Kodaikanal southwards, the base of the $F$ region is also subjected to this driving force, in fact more effectively, because the ionneutral coupling is stronger in the lower $F$ region than at the peak. This will cause an increase in $\mathrm{h}^{\prime} \mathrm{F}$ and is seen in the ionograms. It may also be noted that due to low ion and neutral densities in the night-time at any given 
altitude in the F region, the ion drag is much less, which is conducive to higher values of equatorward nocturnal winds. Once the winds arrive at the low latitudes the horizontal nature of the magnetic field allows the free flow of the neutral air along with the plasma in a horizontal direction. This is unlike the situation at the mid-latitudes, where the horizontal neutral winds are impeded by the propensity of the plasma to move along the non-horizontal magnetic field lines.

\section{Conclusions}

Departures in the F-region parameters for a large number of intense magnetic storms were studied in detail at equatorial latitudes using ionosonde data. Several outstanding features were observed, but one major feature was sudden collapse of F-region ionisation in the post-midnight period. The fact that the collapse was consistently associated with a marked increase in the F-region height defies an easy explanation using conventional ideas. It is proposed that an intensification of eastward electric field (due to magnetospheric processes) may enhance upward drift of the ionisation followed by rapid transport to higher latitudes, as in the fountain effect of the Equatorial Anomaly. Another possibility is the ionisation in the bottomside being swept by equatorward winds: selectively removing it up to the $\mathrm{F}$ peak, yielding the apparent results of an increase in $h^{\prime} F$.

Acknowledgements. Topical Editor D Alcaydé thanks K.I. Oyama and $\mathrm{G}$. Bailey for their help in evaluating this paper.

\section{References}

Aarons, J., The role of the ring current in the generation or inhibition of equatorial F-layer irregularities during magnetic storms, Radio Sci., 26, 1131-1149, 1991.

Abdu, M. A., G. O. Walker, B. M. Reddy, J. H. A. Sobral, B. G. Fejer, T. Kikuchi, N. B. Trevedi, and E. P. Szusxczewicz, Electric field versus neutral wind control of the equatorial anomaly under quiet and disturbed conditions; a global perspective from SUNDIAL' 86, Ann. Geophysicae, 8, 419-430, 1990.

Biondi, M. A., and J. W. Meriwether Jr, Measured response of the equatorial thermospheric temperature to geomagnetic activity and solar flux changes, Geophys. Res. Lett., 12, 267-270, 1985

Biondi, M. A., J. W. Meriwether Jr, B. G. Fejer, S. A. Gonzalez, and D.C, Hellenbeck., Equatorial thermospheric wind changes during the solar cycle: Measurements at Arequipa, Peru, from 1983 to 1990, J. Geophys. Res., 96, 15917-15930, 1991.

Dabas, R. S., and A. R. Jain, Geomagnetic storm effects in ionospheric TEC at an equatorial station: contribution of $\boldsymbol{E} \times \boldsymbol{B}$ drifts and meridonal neutral winds, Indian J. Radio Space Phys., 14, 100-106, 1985.
Dabas, R. S., D. R. Lakshmi, and B. M. Reddy, Effect of geomagnetic disturbances on the VHF nighttime scintillation activity at equatorial and low latitudes, Radio Sci., 24, 563-573, 1989.

Fejer, B. G., R. W. Spiro, and J. C. Foster., Latitudinal variations of perturbation electric fields during magnetically-disturbed period: 1986 SUNDIAL observation and model results, Ann. Geophysicae , 8, 441-454, 1990.

Fuller-Rowell, T. J., M. V. Codrescu, R. J. Moffett, and S. Quegan., Response of the thermosphere and ionosphere to geomagnetic storms, J. Geophys. Res., 99, 3893-3914, 1994.

Gross, H. S., Unusual heating events at about $250 \mathrm{~km}$ altitude at very low latitudes seen by AE-E, J. Atmos. Terr. Phys., 47, 941945, 1985

Hedin, A. E., MSIS-86 thermospheric model, J. Geophys. Res., 92, 4649-4662, 1987.

Krishna Murthy, B. V., and S. S. Hari., Equatorial night-time thermospheric meridional winds: seasonal variations and magnetic activity effects, Proc. STEP Symp., COSPAR, 477-480, 1992.

Krishna Murthy, B. V., S. S. Hari, and V. V. Somayajulu, Nighttime equatorial thermospheric meridional winds from ionospheric h'F data, J. Geophys. Res., 95, 4307-4310, 1990.

Lakshmi, D. R., B. M. Reddy, and S. Shastri, A prediction model for equatorial and low-latitudes HF communication parameters during magnetic disturbances, Indian J. Radio Space Phys., 12, 118-123, 1983.

Lakshmi, D. R., B. C. N. Rao, A. R. Jain, M. K. Goel, and B. M. Reddy, Response of equatorial and low-latitude F-region to the great magnetic storm of 13 March 1989, Ann. Geophysicae, 9, 286-290, 1991.

Matsushita, S., A study of morphology of ionospheric storms, J. Geophys. Res., 64, 305-321, 1959.

Meriwether, J. W., J. W. Moody, M. A. Biondi, and R. G. Roble, Optical interferometric measurements of night-time equatorial thermospheric winds at Arequipa, Peru, J. Geophys. Res., 91, 5557-5566, 1986.

Miller, K., D. G. Torr, and P. G. Richards, Meridional winds in the thermosphere derived from measurement of F2-layer height, $J$. Geophys. Res., 91, 4531-4535, 1986.

Raja Ram, G., and R. G. Rastogi, A synoptic study of the disturbed ionosphere during IGY--IGC (1) the Asian Zone, Ann. Geophysicae, 25, 795-805, 1969.

Raja Ram, G., A. C. Das, and R. G. Rastogi, Ionospheric F-region disturbances and their possible mechanisms, Ann. Geophysicae, 27, 469-475, 1971.

Reddy, B. M., L. H. Brace, and J. A. Findlay, The ionosphere at 640 kilometers on quiet and disturbed days, J. Geophys. Res., 72, 2709-2727, 1967.

Rishbeth, H., F-Region storms and thermospheric circulation, $J$. Atmos. Terr. Phys., 37, 1055-1064, 1975.

Rush, C. M., D. Miller, and J. Gibbs, The relative daily variability of foF2 and $\mathrm{hmF} 2$ and their implications for $\mathrm{HF}$ radio propagation, Radio Sci., 9, 749-756, 1974.

Sahai, Y., J. A. Bittencourt, H. Takashashi, N. R. Teireira, J. H. A. Sobral, B. A. Tinsley, and R. P. Rohrbaugh, Multispectral optical observations in ionospheric F-region storm effects at low latitude, Planet. Space Sci., 36, 371-381, 1988.

Tinsley, B. A., Energetic neutral atom precipitation as a possible source of mid-latitude F-region winds, Geophys. Res. Lett., 6, 291-293, 1979. 